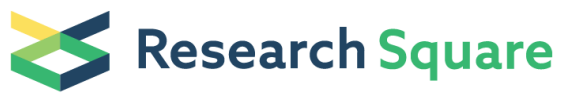 \\ Preprints are preliminary reports that have not undergone peer review. \\ They should not be considered conclusive, used to inform clinical practice, or referenced by the media as validated information.
}

\section{Chromosomal Abnormality in Fetuses with Isolated Antenatal Hydronephrosis: Update for Prenatal Diagnosis and Genetic Counseling}

\author{
Xiaoyan Zhou \\ Huaian First People's Hospital \\ Yan Wang \\ Changzhou Women and Children's Hospital \\ Lulu Meng \\ Women's Hospital of Nanjing medical University \\ Jianxin Tan \\ Women's hospital of Nanjing Medical University \\ Fengchang Qiao \\ Womens and Childrens Hospital of Nanjing University \\ Ping $\mathrm{Hu}$ \\ Women "hospital of Nanjing Medical University \\ Zhengfeng Xu ( $\nabla_{\text {njxzf@126.com ) }}$ \\ https://orcid.org/0000-0002-7824-7578
}

\section{Research}

Keywords: chromosomal microarray analysis, antenatal hydronephrosis, copy number variations, prenatal diagnosis, aneuploidies

Posted Date: June 8th, 2020

DOI: https://doi.org/10.21203/rs.3.rs-28413/v1

License: (c) (i) This work is licensed under a Creative Commons Attribution 4.0 International License. Read Full License 


\section{Abstract}

Background: The prenatal finding of fetuses with antenatal hydronephrosis (ANH) gives a significant dilemma for the clinicians. Which patients require invasive prenatal diagnosis? Though previous literatures have recommended the use of chromosomal microarray analysis (CMA)for fetuses with CAKUT, the cutoff value for CMA have no current consensus on fetuses with ANH. In this article, we aimed to detect chromosomal abnormalities in fetuses with isolated severe ANH (anterior-posterior renal pelvic diameter (APRPD) $\geq 10 \mathrm{~mm}$ ) by CMA, summarized the literatures and proposed recommendations for the prenatal genetic diagnosis according to APRPD.

Methods: Fetuses $(n=84)$ with isolated severe ANH (APRPD $\geq 10 \mathrm{~mm}$ ) were evaluated by CMA. According to APRPD measurements at second trimester, we classified the cases into two groups: (1) Group A: cases with APRPD of 10-15 mm(N=57);(2) Group B: cases with APRPD $\geq 15 \mathrm{~mm}(\mathrm{~N}=27)$. The prenatal and postnatal outcomes were assessed by ultrasonic examination and telephone follow-up.

Results: Overall, one case with 18 trisomy was identified. Clinically significant copy number variants (pathogenic or likely pathogenic CNVs)_were identified in $11.9 \%$ (10/84) cases, including_3.5\% (3/84) of pathogenic CNVs. The detection rates were $5.2 \%(3 / 57), 25.9 \%$ (7/27) for group A and group B, respectively. There was statistically significant differences in the frequency of clinic significant CNVs in the two groups $(p \otimes 0.05)$.

Conclusion: $C M A$ is valuable in prenatal genetic diagnosis of fetuses with severe ANH $₫ A P R P D \geq 10 \mathrm{~mm} \rrbracket$, regardless of whether other ultrasonic abnormalities were observed. This cohort should be followed up during the pregnancy.

\section{Introduction}

Antenatal hydronephrosis (ANH) or pyelectasis refers to dilation of the renal pelvis and calices. It is one of the most common abnormalities among the prenatal ultrasound screening affecting approximately $1-5 \%$ of all pregnancies ${ }^{[1]}$.According to APRPD measurements during the second trimesters, the degrees of ANH were classified to mild(APRPD $4 \mathrm{~mm}-7 \mathrm{~mm}$ ), moderate(APRPD7mm-10 mm), and severe AHN( $\geqq 10 \mathrm{~mm})^{[2]}$.In more than half of the cases, these findings resolve spontaneously by the end of gestation or during the first year of life. However, There was a significant increased risk of postnatal pathology per degree, showing pathologic outcomes including ureteral reflux(VUR), obstructive uropathy ( OU: including ureteropelvic junction obstruction, ureterovesical junction obstruction and congenital megaureter) and so on ${ }^{[3]}$,

Pathologic ANH has been associated with an increased risk of genetic disorders. For instance, Miguel Verbitsky performed a largest study on the copy number variants (CNVs) landscape of congenital anomalies of the kidney and urinary tract (CAKUT). Among the subcategories, cases with VUR were affected by a high CNV burden 37.2\%(245/659) of cases with CNVs( $\geq 100 \mathrm{~kb}), 38.9 \%(199 / 512)$ of cases with OU were reflected by CNV burden( $\geq 100 \mathrm{~kb}$ ) ${ }^{[4]}$; Faure found thirteen CNVs identified in 12 boys with posterior urethral valves (29\% of the cohort), including two pathogenic CNVs and 11 of unknown significance ${ }^{[5]}$.

In the prenatal domain, the isolated fetal pyelectasis during second-trimester targeted ultrasound was reported to be soft marker associated with trisomy $21^{[6]}$.

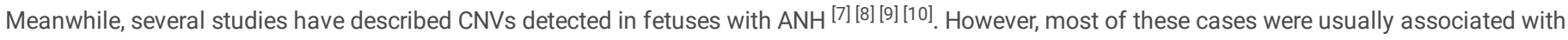
additional ultrasound abnormalities. Moreover, these literatures have not comprehensively investigated the risk of CNVs with varying degrees of APRPD or those aspects of ANH that predict chromosome abnormality. Our study focus on the isolated ANH, we performed chromosomal microarray analysis (CMA) to identify chromosomal abnormalities in the fetuses with severe ANH(APRPD $\geqq 10 \mathrm{~mm}$ ) to determine whether or not the degree of ANH is associated with the risk of CNVs and the recommended cutoff value for CMA.

\section{Results}

\section{Diagnostic yield of CMA testing for fetuses with ANH}

We analyzed a total of 84 prenatal cases of ANH by CMA. These cases had no other sonographic findings except ANH. The overall diagnostic yield of CMA testing for fetuses with ANH was 25\% (21/84), including 1 trisomy 18 and 20 CNVs. Among the detected CNVs, clinically significant CNVs (pathogenic and likely pathogenic) were identified in $11.9 \%$ (10/84) cases, including $3.5 \%(3 / 84)$ of pathogenic CNVs. The incidence rates of clinically significant CNVs were $5.2 \%(3 / 57)$ and $25.9 \%(7 / 27)$ in Group A and Group B, respectively. There were statistically significant differences in the incidence rates of all CNVs and clinically significant CNVs between the two groups ( $p \otimes 0.05$; Table 2$)$ the maternal age, gestational age at amniocentesis and parity did not differ between the two groups according to $t$ tests and Chi-squared tests. Additional details are presented in Table 1.

Table 1

Clinical characteristics of the pregnant woman between Group A compared to Group B

\begin{tabular}{|c|c|c|c|}
\hline $\begin{array}{l}\text { Group A } \\
\mathrm{N}=57\end{array}$ & $\begin{array}{l}\text { Group B } \\
N=27\end{array}$ & p-Value & \\
\hline Maternal age (year) (Mean \pm SD) & $25.05 \pm 1.24$ & $25.40 \pm 1.11$ & $0.047^{\mathrm{a}}$ \\
\hline GA at screening (days) (Means \pm SD) & $29.38 \pm 4.45$ & $29.59 \pm 4.59$ & $0.017^{\mathrm{a}}$ \\
\hline Parity(n) (Means $\pm S D)$ & $1.92 \pm 0.72$ & $1.96 \pm 0.14$ & $0.021^{\mathrm{a}}$ \\
\hline
\end{tabular}


Table 2

Summary of the detection rates of microarray from pregnancies with isolated ANH

\begin{tabular}{|c|c|c|c|c|c|}
\hline Group & $\mathbf{n}$ & $\begin{array}{l}\text { All CNVs detected by CMA } \\
\mathrm{n}(\%)\end{array}$ & $\begin{array}{l}\text { Clinically significant } \\
\text { CNVs } \\
\mathrm{n}(\%)\end{array}$ & $\begin{array}{l}\text { Vous } \\
\mathrm{n}(\%)\end{array}$ & $\begin{array}{l}\text { Benign CNVs } \\
\mathrm{n}(\%)\end{array}$ \\
\hline Group A (APRPD $10-15 \mathrm{~mm}$ ) & 57 & $11(19.2 \%)^{a}$ & $1+2(5.2 \%) b$ & 7 & 1 \\
\hline $\begin{array}{l}\text { Group B (APRPD } \geqq \\
15 \mathrm{~mm})\end{array}$ & 27 & $14(51.8 \%)^{a}$ & $2+5(25.9 \%)^{b}$ & 4 & 3 \\
\hline Total & 84 & 26 & $3+7$ & 11 & 4 \\
\hline
\end{tabular}

Fetuses with APRPD of $10-15 \mathrm{~mm}$

In group A, CNVs were detected in 10.5\% (6/57) cases, included three clinically significant CNVs, one benign CNV, and two VOUS. We compared the frequency of clinically significant CNVs with that in the control cohort in Chinese population ${ }^{[14]}$. The detected rate of clinically significant CNVs in group A was significantly higher than that in the control cohort ( $3 / 57 \mathrm{vs.} 9 / 3748, \mathrm{P}=0.0)$. In case 2 (table3), the deleted region on chromosome15q11.2( $0.47 \mathrm{Mb})$ overlapped with the $100 \%$ region of proximal 15q11.2 microdeletion/microduplication syndrome between BP1 and BP2, $10 \%$ CDS region of NIPA1 gene [OMIM: 608145] and 8.22\% region of Prader-Willi syndrome (Type 1)/Angelman syndrome (Type 1). The mutation of NIPA1 gene [OMIM: 608145] is associated with spastic paraplegia 6 (SPG6) [OMIM: 600363], and SPG6 is autosomal dominant and imperfect inadequacy. The patient is mainly characterized by lower limb paralysis and sphincter disorders [PMID:25689425]; 15q11.2 BP1-BP2 deletion syndrome was with wide phenotypic variability and low penetrance, therefore, we assumed the deletion fragment was likely pathological. We detected a pathogenic deletion region on chromosome $17 q 12$ in Case 6(table 3),involving 99.97\% region of RCAD (renal cysts and diabetes)syndrome. The deletion fragment contains three single dose-sensitive genes: HNF1B ZNHIT3 gene [OMIM: 604500]and PIGW gene [OMIM: 610275]. The mutation in ZNHIT3 gene is associated with PEHO syndrome (PEHO) [OMIM: 260565], leading to tension decreased, mental retardation, optic atrophy, cerebellum and brain stem atrophy, myelination disorder etc; The mutation in PIGW gene is associated with mental responsive syndrome-5 (HPMRS5) [OMIM: 616025], leading to neonatal hypotonia, mental retardation, epilepsy, special face and so on.

\section{Fetuses with APRPD of $15 \mathrm{~mm}$ or more}

In Group B, CNVs were identified in 51.8\% (14/27) cases(table 3), including seven clinically significant CNVs and four VOUS and three benign CNVs. Pathogenic CNVs were detected in Case 10 and case 3. Case 3 in table 3 had a 1.31 Mb deletion in chromosome 2q22.3q23.1 containing methyl-cp G-binding domain 5 (MBD5, MIM611472). Deletion in MBD5 is linked to 2q23.1 deletion syndrome characterized by moderate or severe mental retardation, seizures, skeletal abnormalities, sleep disturbance, significant speech impairment, and autistic-like behavioral problems. ORC4 gene in this deletion region is associated with Meier-Gorlin syndrome (MGS), MGS is a rare autosomal recessive primordial dwarfism disorder, characterized by microtia, patellar applasia/hypoplasia, and a proportionate short stature ${ }^{[15]}$.In case 10(table 3 ), a de novo deletion fragment in $17 q 12$ region covered $99.97 \%$ region of RCAD (renal cysts and diabetes) syndrome.

The genetic variants were not inherited from their parents in case 4, 5, 7,8 and case 9(table 3). Moreover, all overlapped with deletion/duplation syndromes or containing OMIM -morbid gene partly, but no definite pathogenic evidence had been reported. Hence, these disorders were classified as likely pathological. In case 4, a de novo deletion of $0.55 \mathrm{Mb}$ was detected on 11p15.5. This repetitive fragment overlapped with 1.79\% region of Homozygous $11 \mathrm{p} 15$-p14 Deletion syndrome [OMIM:606528], known as congenital hyperinsulinism $(\mathrm{CHI})$ and profound hearing loss ${ }^{[16]}$. In Case 8 , a de novo duplation in $15 q 13.3$ region overlapped with $97.84 \%$ region of $15 q 13.3$ recurrent region (D-CHRNA7 to BP5) (includes CHRNA7 and OTUD7A) duplication[ClinGen:ISCA-46295] and 33.26\% region of 15q13.3 recurrent region (BP4-BP5) (includes CHRNA7) duplication[ClinGen:ISCA-37411]. In case 9, a de novo deletion fragment of 11p15.5 was shown to be overlap with 1.79\% region of 11p15-p14 deletion syndrome (homozygous)[OMIM:606528],which contained 100.00\% CDDS region in classical transcripts of CTSD gene [OMIM:116840], 100\% CDS region in TNN/2 gene and 100\% CDS region in $\mathrm{H} 19$. The mutation of CTSD gene is associated with neuronal ceroid lipofuscinosis-10 (CLN10)[OMIM:610127] which is autosomal recessive inheritance, is characterized by respiratory failure, vision loss, ataxia, microcephaly, mental retardation, etc. $\mathrm{H19}$ gene is associated with Beckwith-Wiedemann syndrome.

\section{Follow-up information}

Eighteen cases were excluded for the following reasons: loss of follow-up $(n=7)$ and elective termination $(n=11)$ including 3 with chromosomal abnormalities, 6 with severe bilateral hydronephrosis, 1 with right ureteral atresia and 1 with congenital renal agenesis. Finally, 66 cases had a complete set of follow-ups during the prenatal and postnatal period. The total rate of normalization was $81.8 \%(54 / 66)$ in uterus or after birth. During postnatal follow-up period, 11 cases $(16.6 \%, 11 / 66)$ were treated with surgery due to pelvic uretero junction obstruction (PUJO) (10/11) and ureter stricture (1/11). For all these children, the treatment of operation was effective, the postoperative renal morphology recovered significantly, and the renal function could be preserved, except one child was suspected to have a nephroblastoma at 8 months of age. None of the children had mental and growth retardation during the follow -up period. 
Table 3

Summary of clinically significant CNVs, identified by CMA in 10 fetuses with isolated ANH

\begin{tabular}{|c|c|c|c|c|c|c|c|c|}
\hline case & $\operatorname{sex}$ & gestational weeks & $\begin{array}{l}\text { APRPD } \\
\text { (cm) }\end{array}$ & locus & $\begin{array}{l}\text { Size } \\
\mathrm{Mb}\end{array}$ & $\begin{array}{l}\text { CNV } \\
\text { classification }\end{array}$ & Inheritance & $\begin{array}{l}\text { Related syndrome } \\
\text { /OMIM gene }\end{array}$ \\
\hline 1 & Male & $26+5$ & $\begin{array}{l}\text { Right } \\
1.16 \mathrm{~cm} \\
\text { Left } \\
0.9 \mathrm{~cm}\end{array}$ & $\begin{array}{l}\text { del } 3 p 26.3 \\
60001- \\
1,453,696\end{array}$ & 1.39 & Likely path & Denovo & CNTN6 \\
\hline 2 & Male & 23 & $\begin{array}{l}\text { Right } \\
1.1 \mathrm{~cm} \\
\text { Left } \\
1.1 \mathrm{~cm}\end{array}$ & $\begin{array}{l}\text { del } 15 q 11.2 \\
22,754,322 \\
-23,221,689\end{array}$ & 0.46 & Likely path & Denovo & $15 q 11.2$ recurrent region (BP1-BP2) deletion syr \\
\hline 3 & Male & $23+3$ & $\begin{array}{l}\text { Right } \\
2.1 \mathrm{~cm} \\
\text { Left } \\
1.65 \mathrm{~cm}\end{array}$ & $\begin{array}{l}\text { del } \\
2 q 22.3 q 23.1 \\
147,855,299 \\
- \\
149,170,115\end{array}$ & 1.31 & Pathogenic & Denovo & ACVR2A, ORC4 \\
\hline 4 & male & 27 & $\begin{array}{l}\text { Right } \\
2.4 \mathrm{~cm} \\
\text { Left } \\
1.7 \mathrm{~cm}\end{array}$ & $\begin{array}{l}\text { dup11p15.5 } \\
1,696,849- \\
2,250,850\end{array}$ & 0.55 & Likely path & Denovo & 11p15-p14 deletion syndrome, \\
\hline 5 & Female & 27 & $\begin{array}{l}\text { Right } \\
2.4 \mathrm{~cm}\end{array}$ & $\begin{array}{l}\text { del 3q22.3 } \\
136240085- \\
138219078\end{array}$ & 1.9 & Likely path & Denovo & $\begin{array}{l}\text { CLDN18, DBR1, DZIP1L, ESYT3, IL20RB, MRAS, } \\
\text { A4GNT,ARMCEP70 } \\
\text {,C8 }\end{array}$ \\
\hline 6 & male & 26 & $\begin{array}{l}\text { Right } \\
1.0 \\
\text { Left } \\
1.1 \mathrm{~cm}\end{array}$ & $\begin{array}{l}\text { del17q12 } \\
34,815,551 \\
-36,347,393\end{array}$ & 1.53 & Path & Denovo & RCAD (renal cysts and diabetes) syndrome \\
\hline 7 & male & 26 & $\begin{array}{l}\text { Left } \\
1.5 \mathrm{~cm}\end{array}$ & $\begin{array}{l}\text { del17q11.2, } \\
29396574- \\
33259042\end{array}$ & 3.8 & Likely path & Denovo & $17 q 11.2$ recurrent region duplication syndrome, \\
\hline 8 & Female & 27 & $\begin{array}{l}\text { Left } \\
1.7 \mathrm{~cm}\end{array}$ & $\begin{array}{l}\text { dup } 15 q 13.3 \\
32,028,804 \\
-32,515,681\end{array}$ & 0.484 & Likely path & Denovo & $\begin{array}{l}\text { 15q13.3 recurrent region (D-CHRNA7 to BP5) (in } \\
\text { OTUD7A) duplication syndrome }\end{array}$ \\
\hline 9 & male & 25 & $\begin{array}{l}\text { Right } \\
2.4 \mathrm{~cm} \\
\text { Left } \\
1.7 \mathrm{~cm}\end{array}$ & $\begin{array}{l}\text { dup11p15.5 } \\
1,696,849- \\
2,250,850\end{array}$ & 0.554 & Likely path & Denovo & $\begin{array}{l}\text { KRTAP,IFITM10,CTSD,SYT8,TNNI2,LSP1,TNNT3 } \\
\text { IGF2,INS,TH }\end{array}$ \\
\hline 10 & female & $27+3$ & $\begin{array}{l}\text { Left } \\
2.0 \mathrm{~mm} \\
\text { Right } \\
1.5 \mathrm{~mm}\end{array}$ & $\begin{array}{l}\text { Dele17q12 } \\
34,815,551 \\
-36,347,393\end{array}$ & 1.53 & path & Denovo & RCAD (renal cysts and diabetes) syndrome \\
\hline
\end{tabular}

CNVs, copy number variants; ANH, antenatal hydronephrosis; dup, duplication; del, deletion; path: pathogenic; CMA: chromosomal microarray analysis;

\section{Discussion:}

Recommendations for fetuses with prenatally diagnosed ANH remain controversial, especially regarding identification of the most accurate and detailed genetic causes. Previous studies have concluded that isolated fetal pyelectasis is related to an increased risk of aneuploidy, more than doubles the odds of trisomy 21 from maternal serum screening test results ${ }^{[6]}$. However, the diagnostic yield of CNVs in fetuses with isolated ANH remains uncertain. Some studies have reported the overall detection rates of pathogenic CNVs varied from 3.2-9\% in fetuses with ANH and $4.5 \%$ of fetuses with isolated ANH ${ }^{[7][8][9][10]}$ (Table 4). In our study, CMA revealed the clinically significant CNVs (pathogenic and likely pathogenic) of $11.9 \%$ (10/84) in fetuses with isolated severe ANH, including pathogenic CNVs of 3.5\% (3/84), similar to that in previous reports. Its results demonstrated the increased risk for clinically significant CNVs in isolated $\mathrm{ANH}$, compared to the general population. These findings strongly supported the practice of routine CMA analysis in pregnancies with isolated several $\mathrm{ANH}$. 
Table 4

Summary of the incremental yield of chromosomal microarray analysis over karyotyping in fetuses with pyelectasis

\begin{tabular}{|c|c|c|c|c|c|c|c|c|c|c|c|}
\hline \multirow[t]{2}{*}{ Study } & \multirow{2}{*}{$\begin{array}{l}\text { Inclusion } \\
\text { criteria } \\
\text { for original } \\
\text { study }\end{array}$} & \multirow{2}{*}{$\begin{array}{l}\text { Degree of } \\
\text { pyelectasis }\end{array}$} & \multicolumn{3}{|c|}{ All pyelectasis } & \multicolumn{3}{|c|}{ Isolated pyelectasis } & \multicolumn{3}{|c|}{ Non-isolated pyelectasis } \\
\hline & & & $\mathbf{n}$ & $\begin{array}{l}\text { Pathogenic } \\
\text { CNVs }\end{array}$ & $\begin{array}{l}\text { Detection rate } \\
\text { of pathogenic } \\
\text { CNVs by } \\
\text { microarray } \\
(\%)\end{array}$ & $\mathbf{n}$ & $\begin{array}{l}\text { Pathogenic } \\
\text { CNVs }\end{array}$ & $\begin{array}{l}\text { Detection } \\
\text { rate of } \\
\text { pathogenic } \\
\text { CNVs by } \\
\text { microarray } \\
\text { (\%) }\end{array}$ & $\mathbf{n}$ & $\begin{array}{l}\text { Pathogenic } \\
\text { CNVs }\end{array}$ & $\begin{array}{l}\text { Detection } \\
\text { rate of } \\
\text { pathogenic } \\
\text { CNVs by } \\
\text { microarray } \\
(\%)\end{array}$ \\
\hline $\begin{array}{l}\text { Shaffer } \\
\text { et al }\end{array}$ & $\begin{array}{l}\text { Various } \\
\text { ultrasound } \\
\text { anomalies }\end{array}$ & Not stated & 95 & $55.2 \%$ & & 24 & 1 & $4.1 \%$ & 71 & 4 & $5.6 \%$ \\
\hline $\begin{array}{l}\text { Jennifer } \\
\text { et al }\end{array}$ & $\begin{array}{l}\text { Various } \\
\text { ultrasound } \\
\text { anomalies }\end{array}$ & $\begin{array}{l}\text { APRPD } \\
>10 \mathrm{~mm}\end{array}$ & 42 & 3 & $7.1 \%$ & 5 & 0 & 0 & 37 & 3 & $8.1 \%$ \\
\hline $\begin{array}{l}\text { Jing } \\
\text { et al }\end{array}$ & $\begin{array}{l}\text { Various } \\
\text { ultrasound } \\
\text { soft } \\
\text { markers }\end{array}$ & $\begin{array}{l}\text { APRPD } \\
5-10 \mathrm{~mm}\end{array}$ & 62 & 2 & $3.2 \%$ & $\begin{array}{l}\text { Not } \\
\text { stated }\end{array}$ & 1 & - & $\begin{array}{l}\text { Not } \\
\text { stated }\end{array}$ & 1 & - \\
\hline $\begin{array}{l}\text { Bardin } \\
\text { et al }\end{array}$ & $\begin{array}{l}\text { Various } \\
\text { ultrasound } \\
\text { anomalies }\end{array}$ & Not stated & 11 & 1 & $9 \%$ & $\begin{array}{l}\text { Not } \\
\text { stated }\end{array}$ & - & - & $\begin{array}{l}\text { Not } \\
\text { stated }\end{array}$ & - & - \\
\hline $\begin{array}{l}\text { Our } \\
\text { study }\end{array}$ & pyelectasis & $\begin{array}{l}\text { Mild to } \\
\text { severe }\end{array}$ & - & - & - & 84 & 3 & $3.5 \%$ & - & - & - \\
\hline
\end{tabular}

The global recommendation on the cutoff value for CMA has not been consensuses. few studies have reported the clinical significance of APRPD of 10$15 \mathrm{~mm}$. It is unclear whether the cutoff value of APRPD 10-15 mm can be applied to CMA and therefore whether fetuses with APRPD of 10-15 mm should be excluded from CMA Accordingly, in this retrospective study, we evaluated the range of APRPD values in isolated ANH for CMA tests. We examined 84 cases and found 10 cases with clinically significant CNVs. There was three case of clinically significant CNVs detected in fetuses with APRPD of 10-15 mm (group A), revealing a $5.2 \%(3 / 57)$ incremental yield.

Meanwhile, the relative risk for clinically significant CNVs in cases with APRPD 10-15 mm was significantly higher than the control population. Although, there is a discrepancy between CNV and maternal age, it has been reported that advanced maternal age only reflected in chromosome aneuploidy,

chromosome structural abnormalities did not increase with the mother's age ${ }^{[17]}$. Moreover, we incorporated fetuses with APRPD of $10 \mathrm{~mm}$ and progressed to determine the cutoff value for application of CMA. Because the value of $10 \mathrm{~mm}$ and less measured at $2 \mathrm{nd}$ Trimester was also the cutoff value for fetal mild bilateral pyelectasis, which was a benign condition especially when the renal pelvis regressed ${ }^{[18][19]}$. Based on these findings, we suggest that cases with APRPD of $10 \mathrm{~mm}$ and further progressed could be offered for invasive procedures.

In cases with APRPD of greater than or equal to $15 \mathrm{~mm}$ (group B), seven cases of CNVs with clinical significance were detected, providing a 25.9\% (7/27) incremental yield of detecting CNVs. the frequency of clinically significant CNVs in group B were obviously higher than that in group A. This result is in accordance with conclusions of previous studies showing that a larger anterio rposterior pelvic diameter (APRPD) is associated with increased likelihood of surgery due to the correspondent higher grade of obstruction and consequently to higher risk of renal function [20]. Therefore, we speculated that the detected rate of clinical significance CNVs increased with their APRPD.

During the follow-up period, no obvious mental and growth retardation were found in all the children. Previous studies have assessed the clinical significance of CNVs in children with CAKUT. Fature et al ${ }^{[21]}$ carried out a follow up study and found that patients with CNVs had a worse prognosis, compared with the control group. Miguel Verbitsky ${ }^{[22]}$ found that patients with pathogenic CNVs had a nominally reduced estimated glomerular filtration rate, elevated cystatin C levels, and increased proteinuria at study enrollment. These studies showed that genomic imbalances could have pleiotropic effects on renal function. In conclusion, compared to fetuses without CNVs, fetuses with CNVs have a relatively poor prognosis in renal function, and should be recommended for close monitoring of renal function after birth.

\section{Conclusions}

The limitation of our study is the small sample size. This was a small study from a single center. Thus, further studies are required to perform multicenter surveys with larger sample sizes in order to confirm our findings. In conclusion, our data suggest an association between CNVs and ANH. The abnormality rate of CNVs increased with their APRPD. CMA should be recommended to fetuses with APRPD $\geqq 10 \mathrm{~mm}$ at 2 nd trimester.

\section{Materials And Methods}


Between January 2011 and August 2019, pregnant women with ANH detected by systemic prenatal ultrasonography were referred to Prenatal Diagnostic Center in Nanjing Maternity and Child Health Care Hospital (Jiangsu, China) and the Affilliate Huaian No.1 people's Hospital(Jiangsu, China). We observed the cases defined as anterior-posterior renal pelvic diameter (APRPD) $>4 \mathrm{~mm}$ in the second trimester. Meanwhile, the cases had no other ultrasound anomalies, including structural anomalies and soft markers. According to APRPD described by Lee et al ${ }^{[11]}$, we classified the ANH into 3 groups at 2 nd Trimester: 1) mild ANH (APRPD 4 to $<7 \mathrm{~mm}$ ), 2) medium ANH (APRPD 7 to $10 \mathrm{~mm}$ ), and 3) severe ANH (APRPD $\geqq 10 \mathrm{~mm}$ ). All the fetuses were checked with at least twice time, which had to be repeated 2-3 weeks. Only the cases that APRPD was unchanged or became worse entered the study. The cases with severe ANH (APRPD $\geqq$ $10 \mathrm{~mm}$ ) underwent invasive aminio puncture. According to APRPD values, the cohort was divided into two groups: those with APRPD of 10-15 mm (Group A) and those with APRPD of $15 \mathrm{~mm}$ or more (Group B). Data for maternal age, gestational age at screening, value of APRPD, parity, karyotype and CMA results were showed in table1 and Fig. 1.

In order to estimate the effect on incidence, we compared the frequency of the clinically significant CNVs (pathogenic and likely pathogenic) with that in the control cohort of Chinese populations, based on a retrospective study by Ye Shi et al ${ }^{[12]}$. The author analyzed 4,224 women (over 35 years old at delivery) who accepted prenatal diagnosis. Among them, 3748 cases with normal ultrasound were referred to invasive testing due to advanced maternal age. In this group, 9 (0.2\%) CNVs with associated clinical significance were reported.

This work was approved by the Medical Ethics Committee of Nanjing Maternity and Child Health Care Hospital. Prenatal genetic counseling was carried out by trained clinical geneticists regarding the advantages and potential risks of CMA, including possible findings of uncertain significance, non-paternity,

consanguinity, and adult-onset diseases.

\section{Chromosomal microarray analysis}

Genomic DNA was extracted from $10 \mathrm{ml}$ amniotic fluid samples using a QIA amp DNA Mini Kit (Qiagen, Germany). Human cyto12 SNP array (IIlumina, San Diego, CA) comprising approximately 300,000 SNP probes with average marker spacing of roughly one probe every $10 \mathrm{~kb}$ was applied for the whole-genome scan. SNP array experiments were performed as previously described in our laboratory ${ }^{[13]}$ and molecular karyotype analysis was performed by KaryoStudio $\mathrm{V}$ 1.4.3.0 (Illumina). Copy number variations (CNVs) were called at an effective minimal resolution of $100 \mathrm{~kb}$ involving at least 10 contiguous probes. Regions of allelic homozygosity (ROHs) were displayed at a threshold of $5 \mathrm{Mb}$. Detected CNVs were evaluated based on a scientific literature review and the following public databases: Database of Genomic Variants (http://projects.tcag.ca/variation/), DECIPHER (http://decipher.sanger.ac.uk/), UCSC (http://genome.ucsc.edu/), and OMIM (http://www.ncbi.nlm.nih.gov/omim). Following the American College of Medical Genetics (ACMG) standards and guideline for interpretation of copy number variants, chromosomal micro deletions/microduplications were classified into three categories: pathogenic CNVs, variants of uncertain significance (VOUS) and benign CNVs. CNVs were defined as pathogenic if 1) the CNVs was documented as clinically significant in multiple peer-reviewed publications, regardless of its penetrance and expressivity, or 2) the CNVs overlapped a smaller interval with clearly established clinical significance. CNVs coinciding with known polymorphic CNVs or have been reported in multiple peer-reviewed publications or databases as benign variants were considered benign. CNVs that did not fit any of the above criteria were considered as VOUS. All above experimental and analytical methods were performed based on the previous report as reference in our laboratory ${ }^{[13]}$. In this study, we reported only pathogenic CNVs and VOUS.

\section{Follow-up study}

Follow-up information was obtained through telephone interview and pregnant women medical records. The results of follow-up included prenatal and postnatal outcome. Prenatal variables included gestational age at spontaneous resolution, whether combined with other structural anomalies, and elective termination. Postnatal outcome included non-favourable outcome and normalization. Normalization was defined as absence of pelvic or ureteral dilatation (APRPD of renal pelvis not detectable or $<5 \mathrm{~mm}$ ) and normal configuration of both kidneys and bladder according to postnatal ultrasound. Non-favourable postnatal outcome was defined as persistent anomalies and need of surgery. The average follow-up period was 3 years.

\section{Statistical analysis}

Statistical analyses were performed on maternal clinical characteristics and experimental results using SPSS software (IBM, SPSS statistics). Categorical data were presented as means and standard deviations, the significance of differences were determined using independent exponent $t$ tests and Chi-squared tests. Results with $p$ values $(p<0.05)$ were considered statistically significant.

\section{Declarations}

\section{Ethics approval and consent to participate}

This study was approved by the Medical Ethics Committee of Nanjing Maternity and Child Health Care Hospital. Informed consent was obtained from parents.

\section{Availability of data and materials}

The datasets used and/or analyzed during the current study are available from the corresponding author on reasonable request

\section{Competing interests}

The authors declare that they have no competing interests

\section{Funding}


This study was sponsored by the National Natural Science Foundation of China $(81602300,81770236,81701427,81671475,81500244,81801445$, 81801373), the Natural Science Foundation of Jiangsu Province (BK20160139, BK20181121), the Project on Social Development of Jiangsu Province (BE2015614), the Project on Maternal and Child Health Talents of Jiangsu Province (FRC201791), and the Nanjing Medical University Science and Technology Development Fund (NMUB2019354).

\section{Author' contributions}

$\mathrm{XYZ}$, YW processed the experimental data, performed the analysis, and drafted the manuscript. $\mathrm{PH}, \mathrm{ZFX}$ were involved in planning and supervised the work. $\mathrm{QC}, \mathrm{LC}$, aided in collecting the patients. All authors discussed the results and commented on the manuscript.

\section{Acknowledgements}

We would like to give honest and sincere appreciation to all the participants in this study, and we sincerely appreciate the contributions made by colleagues from Obstetrics and Gynecology Hospital Affiliated to Nanjing Medical University.

\section{References}

1. Mallik M, Watson AR. antenatally detected urinary tract abnormalities: more detection but less action. Pediatr Nephrol. 2008;23(6):897-904.

2. Lee RS, Cendron M, Kinnamon DD, Nguyen HT. Antenatal Hydronephrosis as a Predictor of Postnatal Outcome: A Meta-analysis. Pediatrics. 2006 Aug;118(2):586-93.

3. De Kort EH, Bam bang OetomoS, Zegers SH. The long-term outcome of antenatal hydronephrosis up to 15 milli metres justifies a noninvasive postnatal follow-up. Acta paediatr 2008 Jun; 97(6):708 - 13.

4. Verbitsky M, Westland R, Perez A, Kiryluk K, Liu Q, Krithivasan P, et al. The copy number variation landscape of congenital anomalies of the kidney and urinary tract. Nat Genet. 2019 Apr;51(4):764.

5. Faure A, Bouty A, Caruana G, Williams L, Burgess T. DNA copy number variants: A potentially useful predictor of early onset renal failure in boys with posterior urethral valves. J Pediatr Urol. 2016 Aug;12(4):227.e1-7.

6. Orzechowski KM, Berghella V. Isolated fetal pyelectasis and the risk of Down syndrome: a meta-analysis. Ultrasound Obstet Gynecol. 2013 Dec;42(6):615-21.

7. ShafferLG RosenfeldJA. DabellMP, CoppingerJ, BandholzAM, EllisonJW, RavnanJB, TorchiaBS, BallifBC, FisherAJ. Detection rates of clinically significant genomic alterations by microarray analysis for specific anomalies detected by ultrasound. Prenat Diagn. 2012 0ct;32(10):986-95.

8. Association of copy number variants with specific ultrasonographically detected

Donnelly JC, Platt LD, Rebarber A, Zachary J, Grobman WA, Wapner RJ. Association of copy number variants with specific ultrasonographically detected.

9. fetal anomalies. Obstet Gynecol 2014 Jul; 124(1):83-90.

10. Wang J, Chen L, Zhou C, Wang L, Xie H, Xiao Y, Yin D, Zeng Y, Tang F, Yang Y. ZhuH, ChenX, ZhuQ, LiuZ, LiuH.Identification of copy number variations among fetuses with ultrasound soft markers using next-generation sequencing. Sci Rep 2018 May 25; 8(1):8134.

11. Bardin R, Hadar E, Haizler-Cohen L, Gabbay-Benziv R, Meizner I, Kahana S, Yeshaya J, Yacobson S, Cohen-Vig L, Agmon-Fishman I, Maya I. Cytogenetic analysis in fetuses with late onset abnormal sonographic findings. JPerinat Med. 2018 Nov;27(9):975-82. 46(.

12. Leers, Cendron M, Kinnamon DD. Antenatal hydronephrosis as a predictor of postnatal outcome: a meta-analysis. Pediatrics. 2006;118:586-96.

13. Shi Y, Ma J, Xue Y, Wang J, Yu B, Wang T. The assessment of combined karyotype analysis and chromosomal microarray in pregnant women of advanced maternal age: a multicenter study. Ann Transl Med. 2019 Jul;7(14):318.

14. Wang Y, Cao L, Liang D, Meng L, Wu Y, Qiao F, Ji X, Luo C, Zhang J, Xu T, Yu B, Wang L, Wang T, Pan Q, Ma D, Hu P, Xu ZPrenatal chromosomal microarray analysis in fetuses with congenital heart disease: a prospective cohort study. Am J Obstet Gynecol 2018 Feb; 218(2):244. e1-244.

15. Shi Y, Ma J, Xue Y, Wang J, Yu B, Wang T. The assessment of combined karyotype analysis and chromosomal microarray in pregnant women of advanced maternal age: a multicenter study. Ann Transl Med. 2019 Jul;7(14):318.

16. de Munnik SA, Hoefsloot EH, Roukema J, Schoots J, Knoers NV, Brunner HG, Jackson AP, Bongers EM. Meier-Gorlin syndrome. Orphanet J Rare Dis. 2015 Sep;17:10: 114.

17. Al Mutair AN, Brusgaard K, Bin-Abbas B, Hussain K, Felimban N, Al Shaikh A. Heterogeneity in phenotype of ushercongenital hyperinsulinism syndrome: hearing loss, retinitispigmentosa,and hyperinsulinemic hypoglycemia ranging from severe to mild with conversion to diabetes. Diabetes Care. 2013 Mar,36(3):557 - 61

18. Shi Y, Ma J, Xue Y, Wang J, Yu B, Wang T. The assessment of combined karyotype analysis and chromosomal microarray in pregnant women of advanced maternal age: a multicenter study. Ann Transl Med. 2019 Jul;7(14):318.

19. Hothi DK, Wade AS, Gilbert R. Mild fetal renal pelvis dilatation-much about nothing. Clin J Am Soc Nephrol. 2009;4:168-77.

20. Ahmad G, Green P. Outcome of fetal pyelectasis diagnosed antenatally. J Obstet Gynaecol. 2005;25:119-22.

21. Policiano C, Djokovic D, Carvalho R, Monteiro C, Melo MA. Graça LM.Ultrasound antenatal detection of urinary tract anomalies in the last decade: outcome and prognosis. J Matern Fetal Neonatal Med. 2015 May;28(8):959-63.

22. Faure A, Bouty A, Caruana G. DNA copy number variants: A potentially useful predictor of early onset renal failure in boys with posterior urethral valves $J$ Pediatr Urol 2016 Aug; 12(4): 227.e1-7. 
23. Verbitsky M, Sanna-Cherchi S, Fasel DA, Levy B, Kiryluk K. Matthias Wuttke. Genomic imbalances in pediatric patients with chronic kidney disease. J Clin Invest. 2015 May;125(5):2171-8.

\section{Figures}

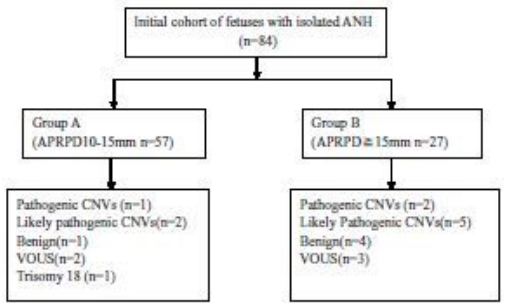

F I G U R E 1 Flowchur of therrant findings frum CMA array andyris of fetwes with

ANH (APRPD greater then or equal to $10 \mathrm{~mm}$ ). CNV, œpy nember veriant, APRPD,

antericr-posterior renal pelvic diameter, CMA, chromosomal microusray analysis

vOUS, variant of unoertain significance

\section{Figure 1}

Figure 1 